\title{
Combination of Contemporary Architecture and Historical Elements in Poetic Methods
}

\author{
Liqun Xiang ${ }^{1,2, a}$, Jianfei Dong ${ }^{1,2, b}$ and Xuezhu Shan ${ }^{1,2, c}$ \\ ${ }^{1}$ School of Architecture, Harbin Institute of Technology, Harbin 150006, China. \\ ${ }^{2}$ Heilongjiang Cold Region Urban-Rural Human Settlements Science Key Laboratory, Harbin \\ Institute of Technology, Harbin 150006, China \\ axinxin910708@163.com, bdongjianfei999@hotmail.com, csxz18646103982@163.com
}

Keywords: Historical Elements; Contemporary Architecture; Combination; Poetic Methods.

\begin{abstract}
Historical elements are loaded with the essence of human civilization. The magnificent and ever-lasting charm is passed down via contemporary architecture, which immerses people in this long path simultaneously. With the diversification of contemporary architecture, large quantities of architecture works have left us with profound impressions and beautiful memories as they successfully inherit the unique historical elements in poetic methods. This paper analyzes silent transforming influence of historical elements over architectural design by comparison of multiple cases, and states the poetic methods when combining contemporary architecture and historical elements.
\end{abstract}

\section{Introduction}

"Poetically dwelling on the earth" becomes what everyone is dreaming about after philosophic interpretation by Heidegger. However, the obscure and disordered expression of the urban architectural style in current times, resulting from either the excessively fast steps of city development, or the misunderstanding of history by contractors and architects, has made residents bewildered, let alone "poetically".

For historical elements, what architects should do is not to mechanically apply historical symbols, but to commit themselves to the multi-level and multi-perspective excavation and interpretation of the history, and to apply its creative use in the design work, so that historical elements and contemporary architecture can be combined poetically and reveal new vitality together.

\section{The Poetic Inheritance of Historical Elements}

\subsection{Inheritance of Original Symbols}

Tadao Ando has ever mentioned two ways to ponder tradition: one that follows traditional forms and the other that inherits the spirit of non-morphology [1]. Kenzo Tange agrees with the former in which the modernization of non-spiritual traditions are inherited and combined with future development; while Tadao Ando believes that the fundamental and spiritual things should be inherited and passed on to the next era.

Kenzo Tange's design of Kagawa Prefectural Government Hall in the year of 1955 (Figure 1) shows his understanding of the "new form of traditional semantics". The building consists an 8-storey office building and a 3-story conference room. Between the two buildings, there is a south-facing courtyard featuring Japanese rock-garden style, which has become a favorite place to rest for the citizens. The outrigger on the structural column is divided into two beams, with each small room divided into five by the concrete beams and slabs, which is quite typical in Japanese traditional wooden buildings [2].

However, the 1980's TIME'S project is more inclined to reflect the Tadao Ando inheritance of traditional spirit. TIME'S is located at the intersection of Takase River and Sanjo Streets in the center of Kyoto. Ando treats Takasago as a garden with different expressions of the seasons and times, and 
TIME'S is designed as a water-aware garden. The three-story building with two on the ground floor and one basement enables you to see the river from any layer. The river has become the meridians of the building, and people, nature and architecture are blending with one another (Figure 2).

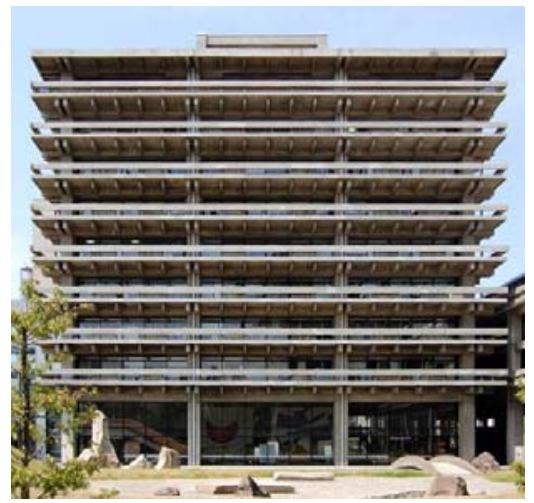

Fig.1 Kagawa Prefecture Hall.

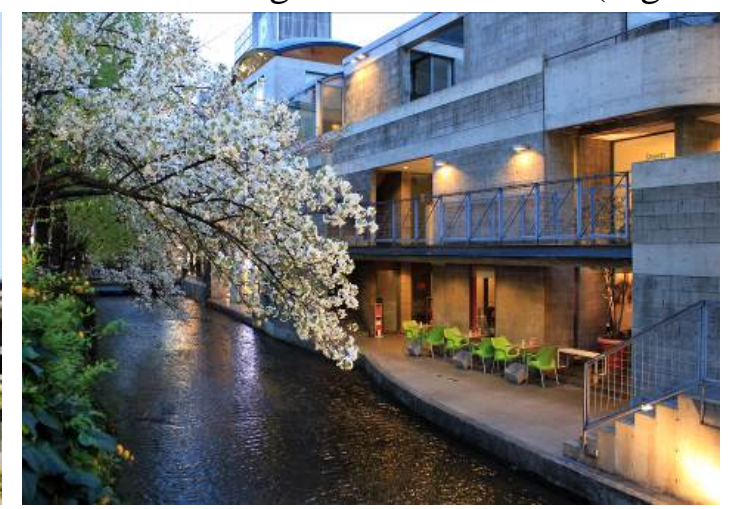

Fig.2 TIME'S.

Both Kenzo Tange's inheritance of the traditional forms and Tadao Ando's inheritance of the non-form spirit are actually the succession of the original symbol. Design works are able to assume unique and poetic attributes by our digging into the characteristics of the original symbols in the traditional civilization, where the architectural space and form are tending to be more diverse.

\subsection{Regeneration of Historical Elements}

The city walks forward unceasingly with the intersection of new and ancient traits, and still has its own life cycle and cultural deposits. The steps of ancient cities are slow, but the city in today turns out a new look every day as the result of the rapid development of science and technology [3]. The aesthetic value of today's society is diverse, and people have more ways to explore how the historical elements in the architecture with the combination of old and new traits are regenerated. It is worth constant thinking and innovation by the architects during their practice.

Rafael Aranda, Carme Pigem and Ramon Vilalta, who received the 2017 Pritzker Architecture Prize, built Barberí Laboratory (Figure 3) as their own office in Olot, Spain at 2007. The building is a former foundry built at the beginning of the 20th century and the three architects chose to remain all of the original industrial building that could remain. They only added new elements where needed in contrasting materials. Barberí Laboratory is comprised of flexible, varied and highly functional spaces. Aranda, Pigem and Vilalta have deep senses and knowledge of history and they use modern construction and materials to create spaces that show their love for both tradition and innovation.

Mr. Wu Liangyong once said: "the composition of the historic city is more like the embroidered clothes which is always worn in life. If it is worn out, it should be darned with its original texture. So, as time goes on, even if it has become the clothes full of patches, it is still a piece of art, with beauty." Rafael Aranda, Carme Pigem and Ramon Vilalta help us to see, that in architecture, international influence and local values can be combined.

\subsection{Worship of Traditional Spirit}

The "Venice Charter", adopted in May 1964, clearly stated: "The historic buildings contain the information passed on from our ancestors, which is a testimony of the old traditions. It is our common responsibility to preserve the ancient monuments as a common heritage, to protect them properly and to communicate the information they contain to the children and grandchildren in the future. "

St. Edward's University Dorms (Figure 4) which is designed by the 2016 Pritzker winner Alejandro Aravena, reflects architect's worship of traditional spirit. Aravena chose khaki bricks as elevation materials in order to coordinate with other buildings in the campus. However, he arranged the bricks in an uneven way to show his understanding of contemporary architecture. He also apply sloping red roofs in St. Edward's University Dorms as the clients required so, but no one can see the red roof directly from the outside. Aravena never imitates traditional symbols mechanically, instead, he insists on applying traditional spirit in fashion ways and thus people can feel the power of life. 


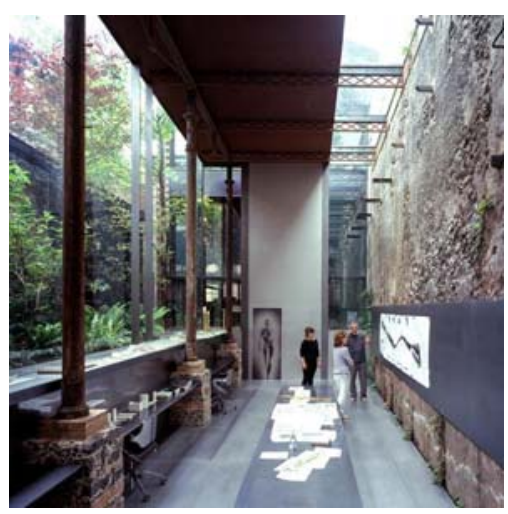

Fig.3 Barberí Laboratory

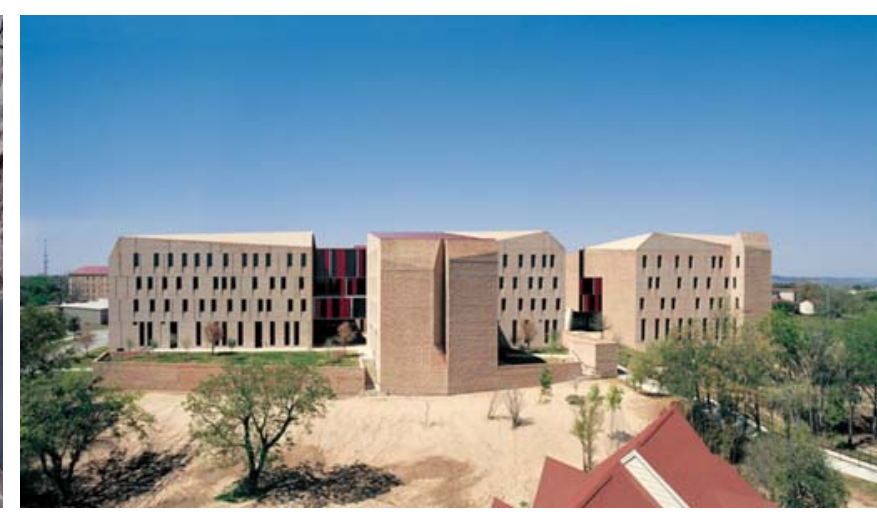

Fig.4 St. Edward's University Dorms

\section{The Creative Interpretation of Contemporary Architecture}

\subsection{Integration of Architectural Spaces}

Poetic architecture is always with the power of warmth, making people wander along but forget the existence of the building itself. This power is often derived from the careful attention to life and the devoted care for sentiments. By integrating architectural spaces in poetic methods, architects can always show natural and social concern from the subtleties of life.

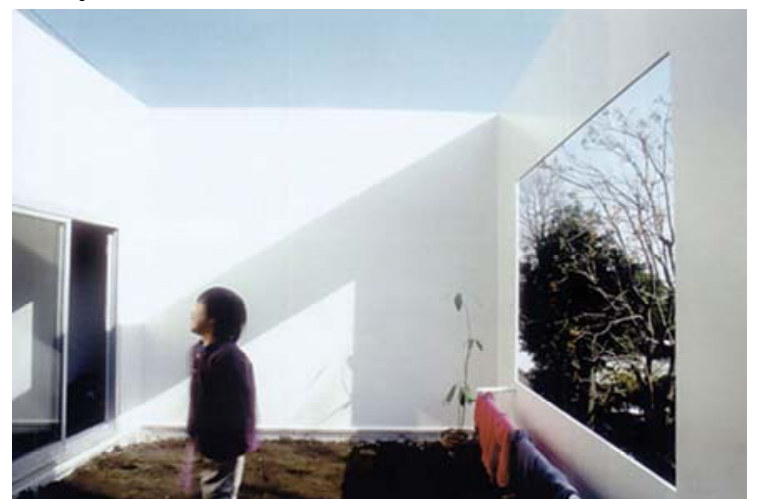

Fig.5 The Openings of House in Plum Grove

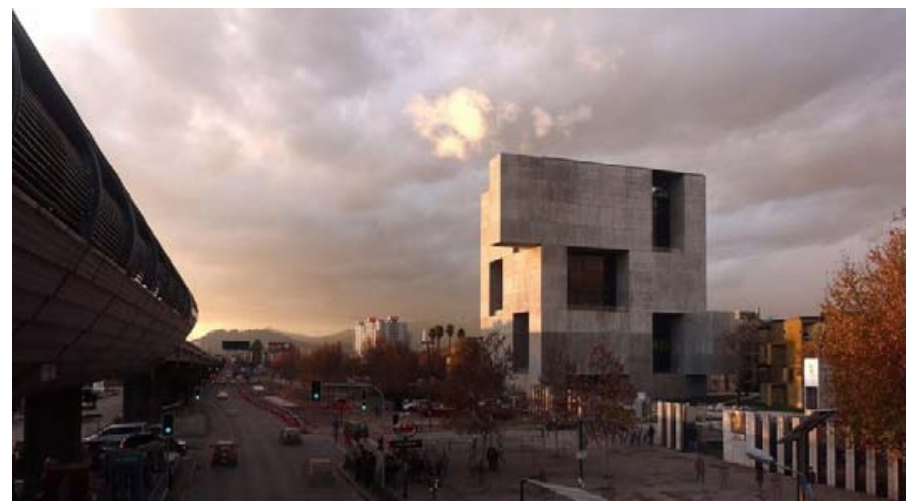

Fig.6 UC Innovation Center

Completed in 2003, the House in Plum Grove (Figure 5) designed by Kazuyo Sejima, is located in a quiet residential area on the outskirts of Tokyo surrounded by rows of plum trees. Kazuyo Sejima did not completely abide by the owner's requirements, to design a "large space" with only one room in a very limited space. Instead, she compressed the bedroom function to the minimum, and the wall into the thinnest, in order to partition several small rooms with independent functions. Therefore, family members can encounter each other somewhere beyond expectation, creating sweet memories.

In UC Innovation Center (Figure 6), Alejandro Aravena has created a rich environment of lively, interesting and welcoming spaces. The interior has many places for spontaneous encounters and transparency that enables viewing activity throughout. Through a reversal of convention, the building is an opaque concrete structure on the exterior and has a light filled glass atrium inside. Aravena's work always shows an understanding of how people will use the facility, and a commitment to creating public spaces to benefit the larger community. In UC Innovation Center, the maturity of him is quite apparent.

\subsection{Representation of Place Spirit}

The building material, as the most intuitive visual response of facade effect, is slowly getting highlighted. Many architects who are well-versed in the use of the materials, like concrete, red brick, glass and other personal building materials, begin to apply them in their personal ideas, and constantly create wonderful works, expressing the unique place spirit of their buildings. Just like Frank Lloyd Wright's description, "For a creative artist, every kind of material has his own message, has his own song" [4]. 
The BOH Visitor Center (Figure 7), which was designed by the ZLG Design team in 2005, is located near a handmade tea-processing factory in Malaysia. With its unique selection of materials and precise control of the site, the team establishes new orders on the basis of preserving the original architecture and the tree in the central area.

Different from the usual wooden gratings, the architectural facade wood is cut into different sized discs (Figure 8) which are stacked in a metal frame, so the building almost don't need mechanical ventilation or air conditioning system. Sunlight penetrates light metal roofs, weakening the inside and outside boundaries of the building, and the building is like floating in the meandering terrain. Strolling in the visitor center, people can enjoy the beautiful scenery and feel the rich and varied space. It seems that they are exposed to the original environment through the natural and skin-friendly materials and medium.

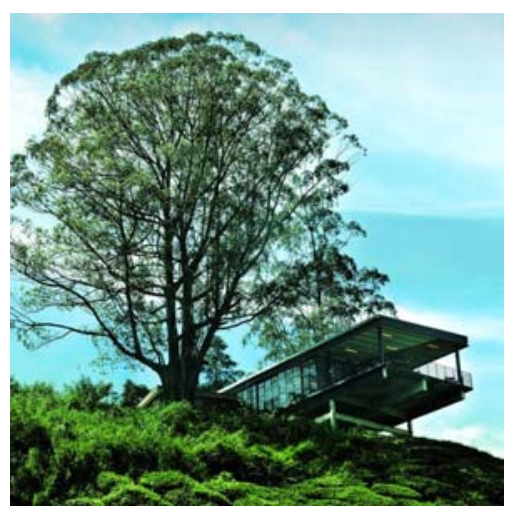

Fig.7 The BOH Visitor Center

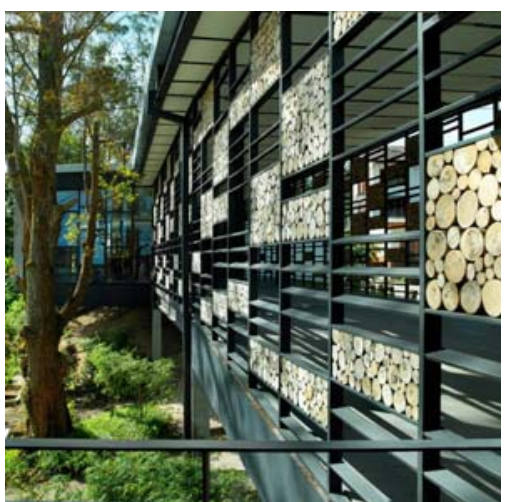

Fig.8 Elevation Materials of

Throughout architectural trends in current times, new materials provide architects with a variety of design ideas and a broader imagination, as well as give birth to ever-changing forms of architecture. Place spirit in the architectural form does not always need to rely on superb skills and gorgeous appearance. The space that is created in a reasonable way with the concern of people's inner needs essentially carries the unique poetic charm, as the result of its intensive characteristics and emotions.

\section{Summary}

The contemporary heritage of historical elements and spirit, as well as the combination of tradition and innovation, are both what architects need to ponder in their design. The poetic methods of combination is derived from the warmth of life. It allows people to enjoy their beautiful time wandering in the building, in the very eyes of the day, among the very ordinary period of time. This kind of warmth is presented in the bizarre realities and is closely related to people's lives. Even the simplest materials, the simplest design will show a clear and inescapable poetic attributes.

\section{Acknowledgments}

This paper is funded by project NSFC 51408166

\section{References}

[1]. Ando, T. Ando Tadao Kenchiku Wo Kataru. Tokyo: University of Tokyo Press. 1999.

[2]. Wu, Y. The inheritance and innovation of Japanese architectural culture: Kagawa Prefecture Hall as an example. Urban Construction Theory Research, 2015, [online] 5(10). Available at: http://d.wanfangdata.com.cn/Periodical/csjsllyj2015102041 [Accessed 7 May 2017].

[3]. Wang, J. Fitting new building with old in historic environment (Master Dissertation). Chongqing: Chongqing University. China 2002. pp.9.

[4]. Xiang, B. Frank Lloyd Wright. Beijing: China Architecture \& Building Press. 1992. 